\title{
Knowledge and Risk Perception toward HIV/AIDS among Students of the University of Prishtina "Hasan Prishtina"
}

\author{
Violeta Zefi \\ Faculty of Social Studies, Masaryk University, Brno, Czech Republic \\ Email: violetazefi@gmail.com \\ Received 24 January 2015; accepted 9 February 2015; published 12 February 2015 \\ Copyright (c) 2015 by author and Scientific Research Publishing Inc. \\ This work is licensed under the Creative Commons Attribution International License (CC BY). \\ http://creativecommons.org/licenses/by/4.0/ \\ (c) (i) Open Access
}

\begin{abstract}
The primary goal of this research paper is to examine knowledge about HIV/AIDS and the perceived risk of infection with HIV among students in Kosovo. The research method used in this study is the quantitative one where data were collected through questionnaire. The survey was conducted with two hundred students of the University of Prishtina "Hasan Prishtina", from four study fields: Department of Psychology, Faculty of Medicine, Department of Chemistry and Faculty of Electrical and Computer Engineering. Knowledge about HIV/AIDS among students was not complete, i.e. they have misconceptions regarding the ways of transmission of HIV virus. The less that students were informed on HIV/AIDS, the higher was their level of stigma. Perception of risk to HIV/AIDS was very low.
\end{abstract}

\section{Keywords}

Level of Knowledge, Risk Perception, HIV/AIDS, Students, University of Prishtina "Hasan Prishtina"

\section{Introduction}

Human Immunodeficiency Virus Infection/Acquired Immunodeficiency Syndrome (HIV/AIDS) as a worldwide pandemic is increasingly being spread in Kosovo. According to the classification system of the United Nations HIV/AIDS Joint Programme (UNAIDS), Kosovo is characterized by a low number of people with HIV/AIDS. However, Kosovo is located in the region of Southeast Europe, which is recognized as one of the regions with the fastest speed of spreading of the HIV epidemic in the world (Kosovar AIDS Committee, 2004-2008).

Although the prevalence of HIV is low, Kosovo has specific elements that may lead to increase of the scale of 
epidemic, if not prevented at early stages. As an economically underdeveloped country, with the highest unemployment rate in the Balkans and with few opportunities for development in many aspects, young people aged 18 - 25 years increasingly face particular challenges that can lead to increased exposure and vulnerability to HIV (Godinho, Jaganjac, Eckertz, Renton, \& Novotny, 2005). Kosovo possesses identifiable factors that put people at risk for infection, such as a very young population, high unemployment, rapid social changes within the family and society, the growing problem of narcotics industry, booming of sex industry, a stigmatized homosexual community, and high rate of population migration, both within and outside of Kosovo.

Researchers conducted after the post-war years in Kosovo showed that there is a low level of knowledge regarding HIV. The research "Knowledge, attitude and habits of youngsters to sexual and reproductive health" showed that among young Kosovars aged 14 - 19, knowledge of sexually transmitted infections and HIV and AIDS are insufficient and that HIV positive people are highly stigmatized (National Institute of Public Health, 2001). Moreover, the research "Knowledge of School Youth on AIDS" (Kosovo Ministry of Health, 2001) has shown that there are many prejudices among students about people living with HIV (Kosovo Ministry of Health, 2001). Based on the findings of this survey, most students prefer to distance themselves from their peers living with HIV/AIDS and think that these people should be treated in special institutions and separated from the rest of people. Results of this research have also shown that although more than $90 \%$ of students know that HIV is not transmitted through the use of shared toilets, only $10 \%$ of them would have used the same toilet as that used by a person infected with HIV (Kosovo Ministry of Health, 2001).

Compared to the early post-war years in Kosovo, the levels of information on HIV/AIDS among young people were increased in the recent years (United Nations Kosovo Team, 2008). The research on "Knowledge, attitudes, practices and behavior of young people in Kosovo in relation to HIV/AIDS” has found that young people are highly informed about HIV/AIDS; 90\% of them have heard about HIV/AIDS. However, less than half (47\%) of them are aware of the difference between these two expressions: HIV/AIDS. The same research has concluded that AIDS is a taboo subject as it is related to sex. There also dominates a strong bias among the general public on the nature of this disease, which is described as "a shameful disease" gained from unrestrained sex, drug addiction, by homosexuals and people who do not care enough about personal hygiene (United Nations Kosovo Team, 2008).

So, based on the aim of this research and the above literature review, the goal of this research was the examination of students' knowledge on HIV/AIDS and the potential risk to become infected with the HIV.

\section{Methodology}

\subsection{Sample}

This research has been conducted using the survey method, which included selection of students who underwent the survey through a self-administered questionnaire. The survey included 200 participants, respectively, 97 female participants and 103 male participants. The sample was structured with 50 participants from each branch of studies, while the participants were selected randomly. The average age was $\mathrm{X}=19.8$, the minimum age being 18 and the maximum one 35. Participants came from 14 municipalities of Kosovo. The sample included participants of four branches of studies at the University of Prishtina: Department of Psychology, Faculty of Medicine, Department of Chemistry and Faculty of Electrical and Computer Engineering. Participants who were in the first year of studies were 167 in total, while the participants who were in the second year of studies were 33 in total.

\subsection{Instrument}

Given that the research aims to measure students' knowledge and as well as perception of risk to HIV/AIDS, the quantitative method, using a questionnaire, was considered to be more appropriate and suitable. The questionnaire was anonymous. The questionnaire contained twenty five questions in total. The first section of the questionnaire contained questions about students' attitudes towards people living with HIV/AIDS. It included twenty questions in total, using the Likert scale as a measuring tool, namely a scale from 1 to 4 , except one question using "Yes" and "No" response options. The second section of the questionnaire contained five questions aimed at determining perception of the risk of becoming infected with HIV, also using the Likert scale as a measuring tool, namely a scale from 1 to 4, 6 and 7, respectively. The demographic data requested are the following: age, gender, permanent residence, municipality, field of studies, marital status, and employment status. In addition to 
demographic data, the questionnaire contained two sections of questions: students' knowledge about HIV/AIDS and perception of the risk toward HIV.

\subsection{Procedure}

The questionnaire was filled out in the premises of the respective faculties (Psychology, Medicine, Chemistry, and Electrical and Computer Engineering) and respondents participated voluntarily. Participants were given clear instructions for filling in the questionnaire.

An informing permission for conducting the research was obtained, with participants informed in advance about the research and its purpose. Confidentiality was guaranteed through data storage and by informing the respondents that the data will be used only for the purposes of this research. Preparation of data processing and control was conducted using the Statistical Package for Social Sciences (SPSS Statistics) application.

\section{Results}

\subsection{Knowledge and Risk Perception of HIV/AIDS}

Results from the survey indicate unsatisfactory level of knowledge among the students about the ways of HIV transmission; respectively, misconceptions regarding means of transmission of HIV/AIDS are evident. A small number of participants have information that HIV cannot be transmitted by using the same toilet seat with someone who living with HIV/AIDS. There are participants from the Department of Psychology and Faculty of Medicine that have accurate knowledge about this question, compared with participants from two other study fields (see Figure 1).

In the higher percentage, participants from urban permanent residence, compared with participants from rural permanent residence, stated correctly the answer that HIV is not transmitted from mosquito bites (see Figure 2).

Participants with different socio-demographic characteristics believe in a high percentage that HIV can be transmitted through social contacts that people make in everyday life such as handshakes and hugs. There are female participants in the survey, compare to male participants, who give more accurate answer with regard to this question (see Figure 3).

A high percentage of participants stated that HIV can be transmitted by eating from the same plate with a person living with HIV/AIDS. The high percentage of wrong answers to these questions are given by participants who came from the Department of Chemistry and Faculty of Electrical and Computer Engineering, comparing to the participants from the Department of Psychology and Faculty of Medicine, who have provided answers accurate (see Figure 4).

There are participants from the Faculty of Medicine of the UP, compared with three other study fields (Psychology, Chemistry and Electrical and Computer Engineering), who in a higher percentage declared that they would be willing to be fed from the same plate with a person living HIV (see Figure 5).

A large part of male stated that they risk of becoming infected with HIV because of a large number of sexual partners and also do not always use a condom. While female have stated in higher percentage that are at risk of getting infected with HIV because their partner have other partners and, another risk according to them, is the risk of blood transfusion.

In general, the main reasons why participants, both male and female, have declared that they are at risk of becoming infected with HIV are: because they have more sexual partners, they do not always use condoms; have used intravenous drugs (they share needles with others) they also stated that their partner have other partners and another risk, according to them, is the risk of blood transfusion (see Figure 6).

Most of participants in urban and rural residence which think that they are at risk of HIV infection are not sexually active. Others believe that they are not at risk of becoming infected because they have only one partner and he/she is faithful; they believe to their partner; always use condoms; then, always use condoms with people who do not know; they do not use intravenous drugs; they do not visit commercial sex workers; never been with anyone infected and a large part of the participants stated that there is no HIV/AIDS in Kosovo (see Figure 7).

\subsection{Impact of Constant (Demographic) Variables on the Knowledge about HIV/AIDS and Risk Perception from HIV/AIDS}

Analysis of relations between gender and the level of knowledge does not show a significant correlation 


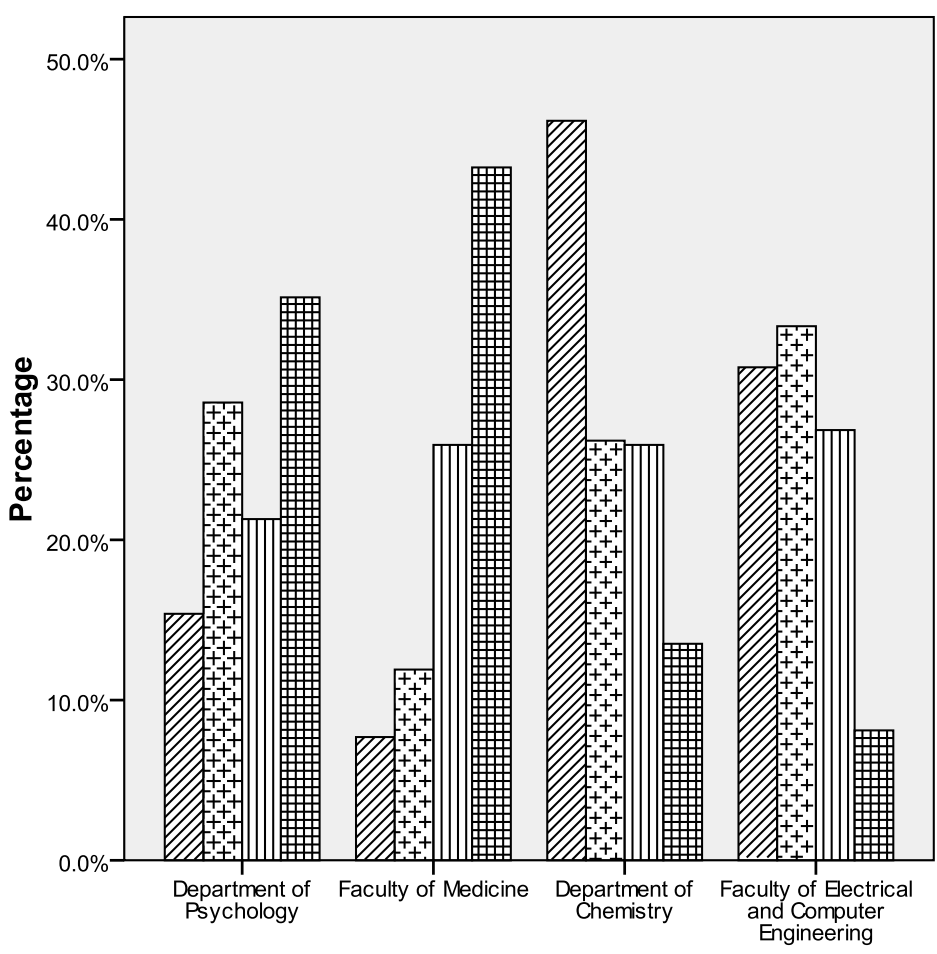

Do you think that you might be infected with HIV by using the same toilet seat with someone who has HIV/AIDS?

$\square$ Strongly agree

$\boxplus$ Agree

III Disagree

囲 Strongly disagree

Field of Study

Figure 1. Do you think that you might be infected with HIV by using the same toilet seat with someone who has HIV/AIDS?

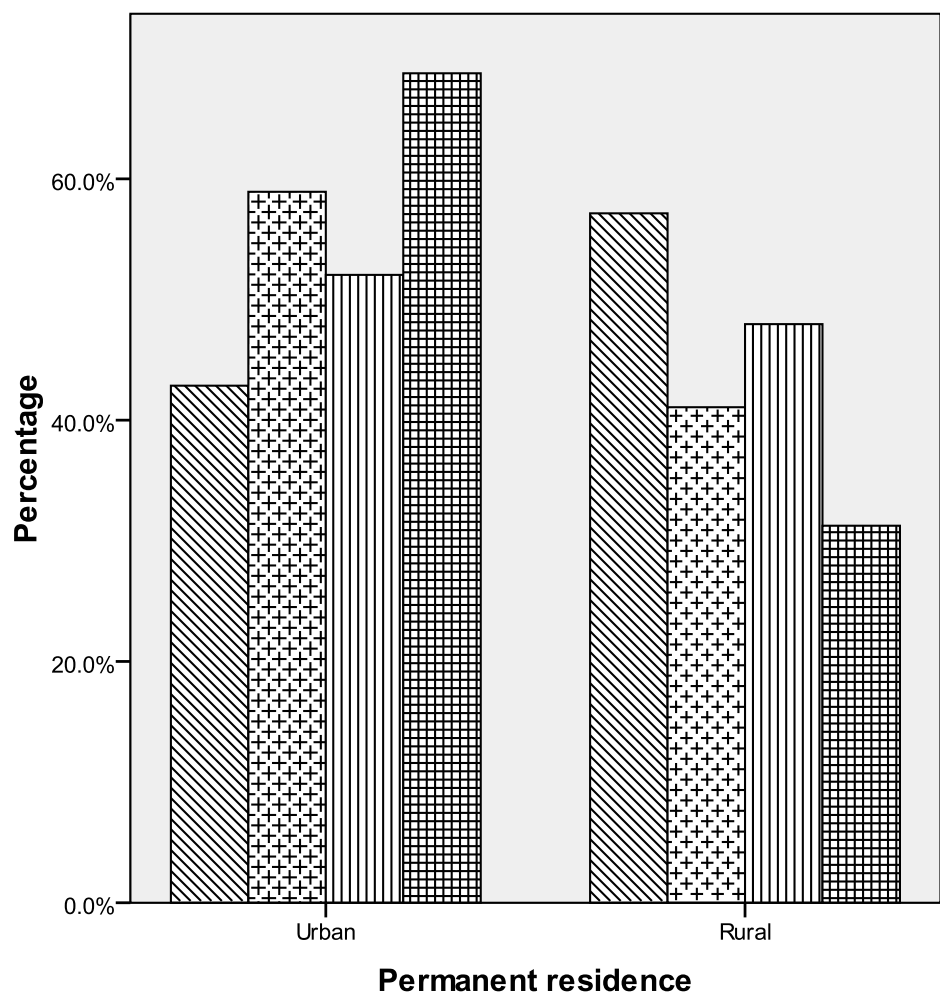

Do you think that you can get infected with HIV from the mosquito bites?

$\mathbb{\$}$ Strongly agree

田Agree

U1 Disagree

囲 Strongly disagree

Permanent residence

Figure 2. Do you think that you can get infected with HIV from the mosquito bites, according to permanent residence? 


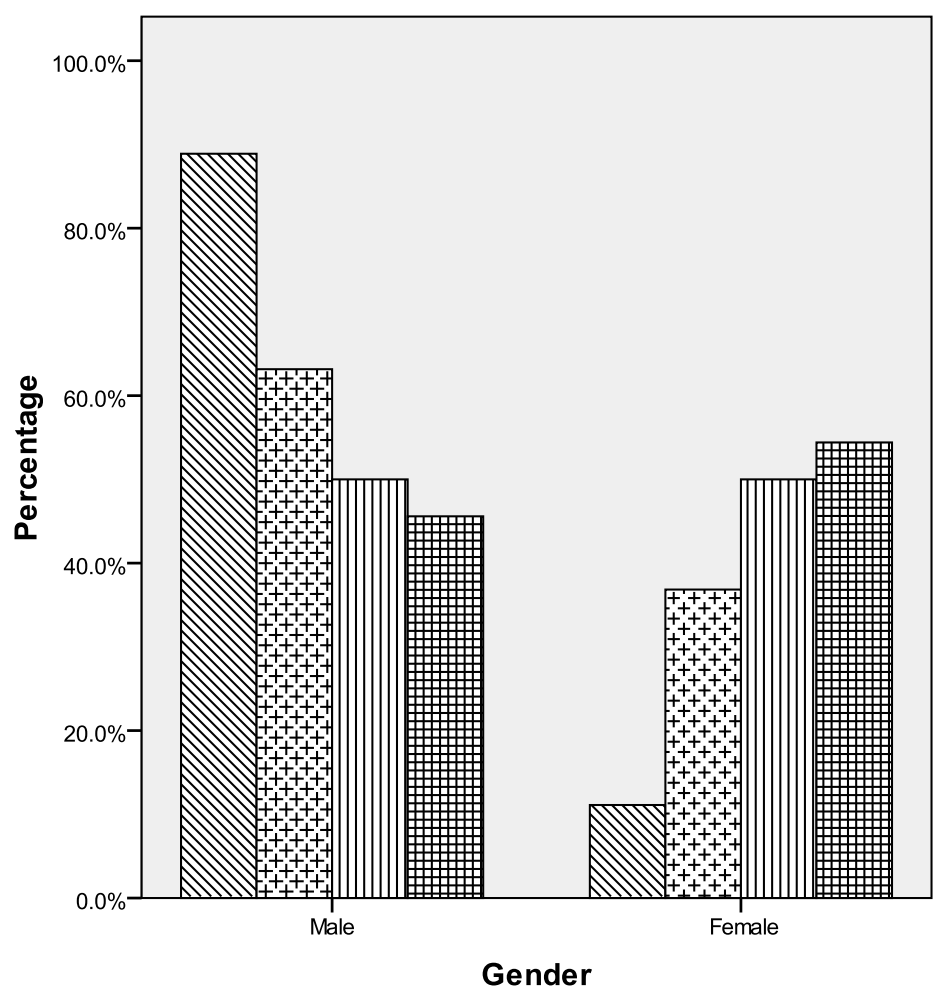

Do you think that you can get infected with

HIV through social contacts that we make in our everyday life (handshakes, hugs)?

DStrongly agree

$\boxplus$ Agree

U1 Disagree

田 Strongly disagree

Figure 3. Do you think that you can get infected with HIV through social contacts that we make in our everyday life (handshakes, hugs), according to gender?

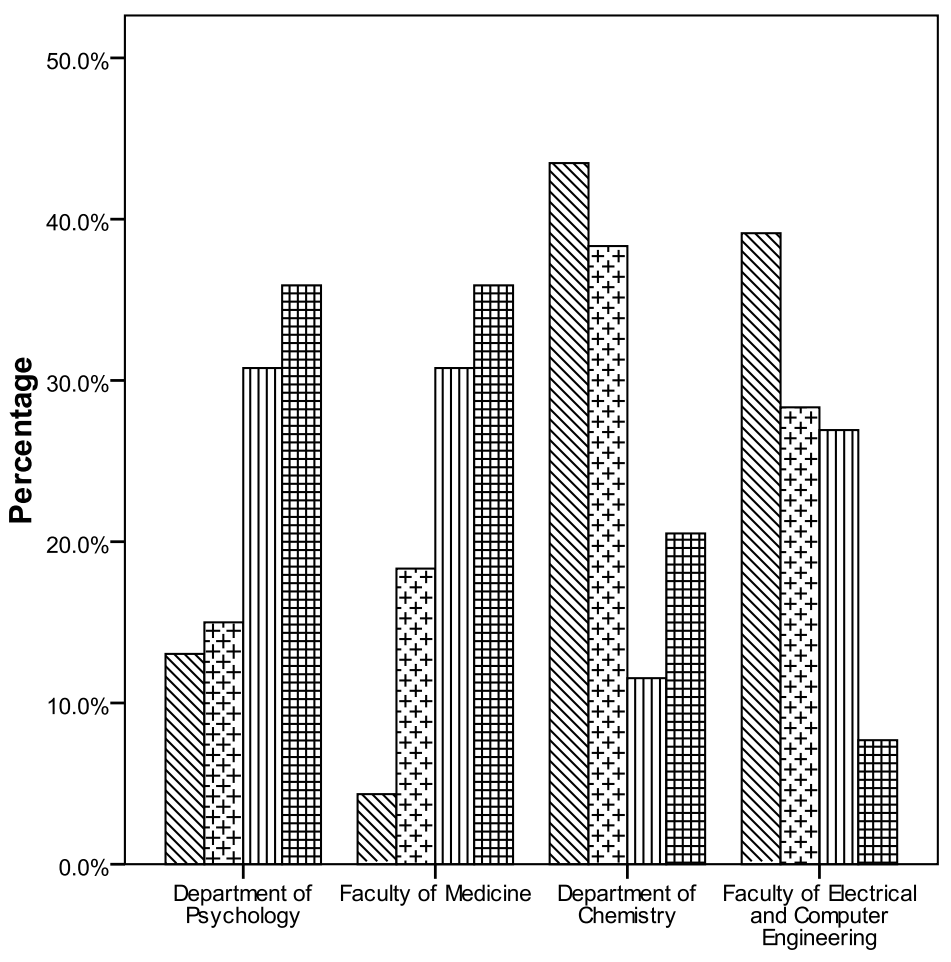

Do you think that you can get infected with HIV being fed from the same plate with a person living with HIVIAIDS

$\mathbb{\$}$ Strongly agree

$\boxplus$ Agree

미 Disagree

团 Strongly disagree

Field of Study

Figure 4. Do you think that you can get infected with HIV being fed from the same plate with a person living with HIV/AIDS, according to the field of study? 


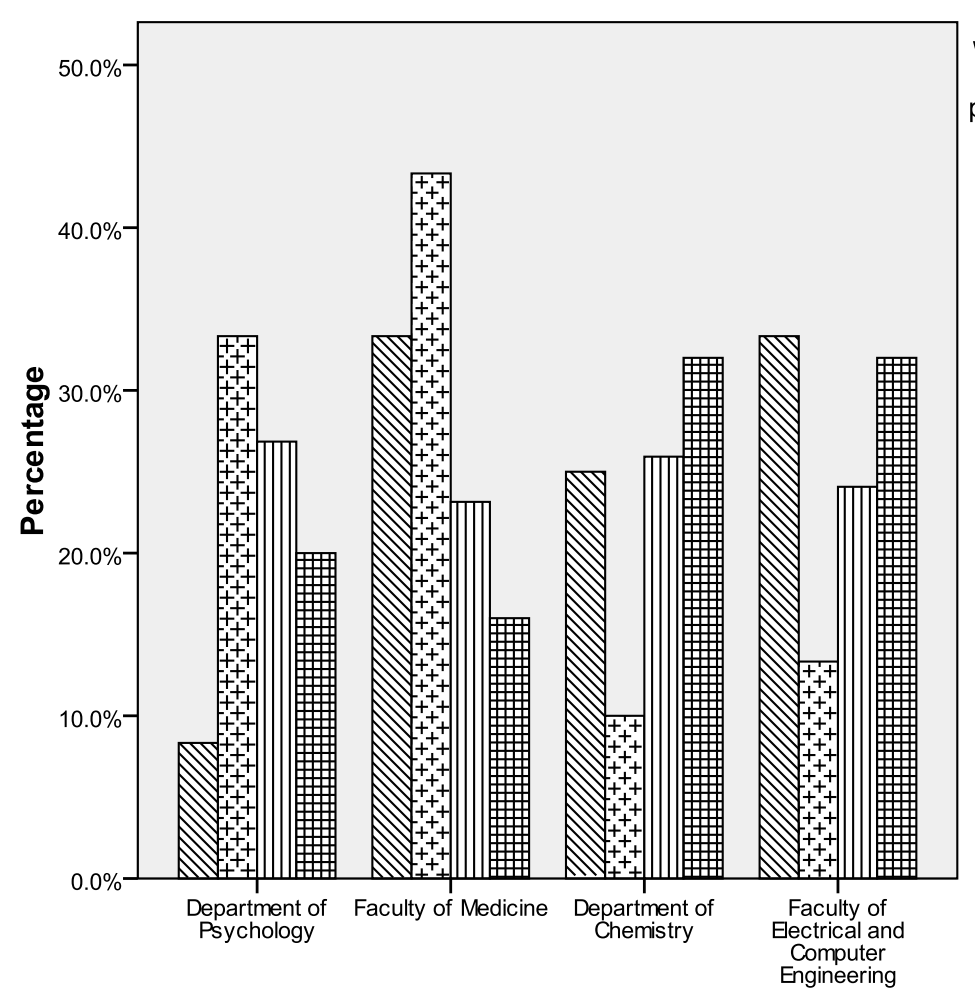

Would you be ready to

be fed from the same plate with a person that you know has HIVIAIDS?

Strongly agree

$\boxplus$ Agree

盂 Disagree

囵 Strongly disagree

Field of Study

Figure 5. Would you be ready to be fed from the same plate with a person that you know has HIV/AIDS, according to the field of study?

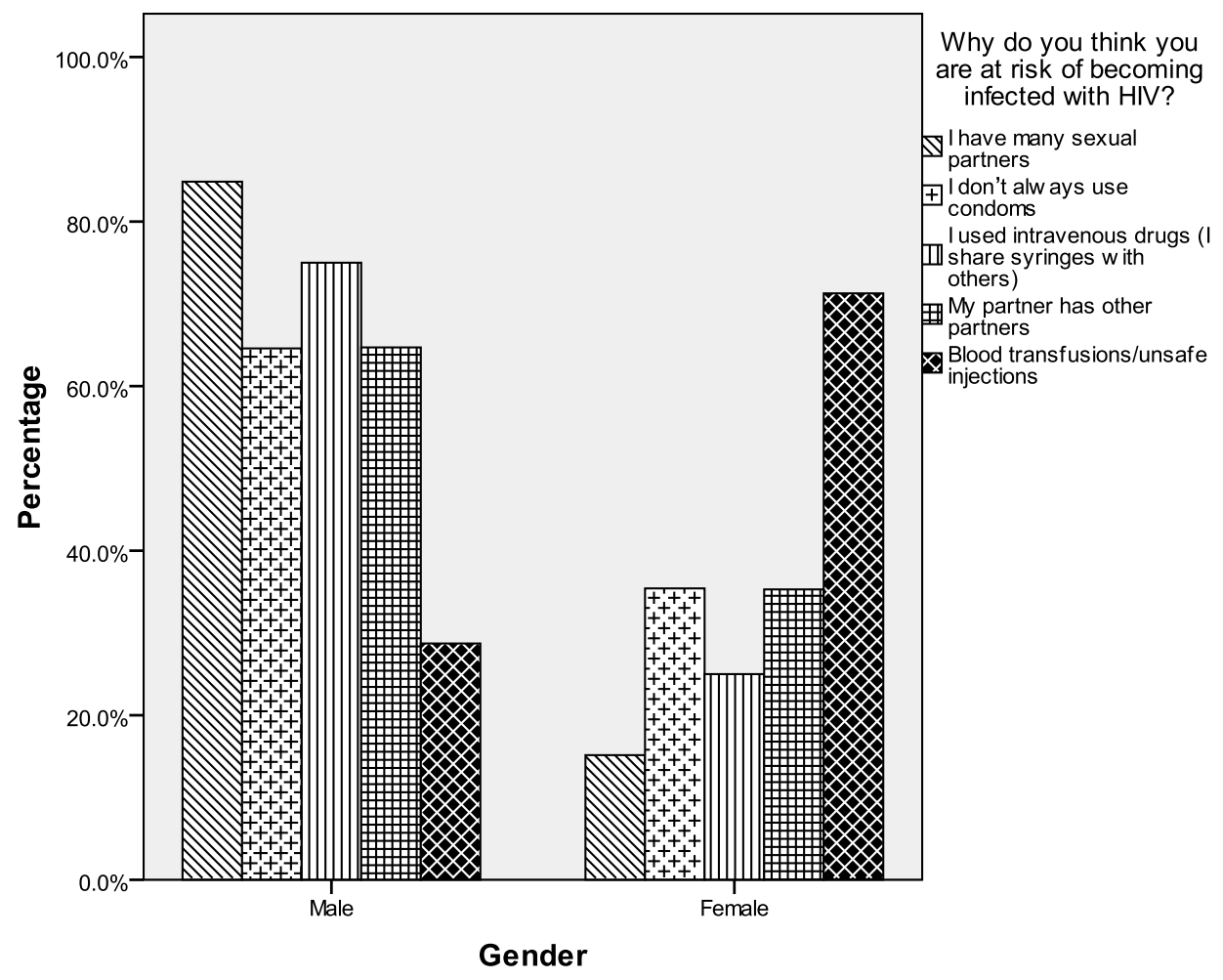

Figure 6. Why do you think you are risk of becoming infected with HIV, according to gender? 


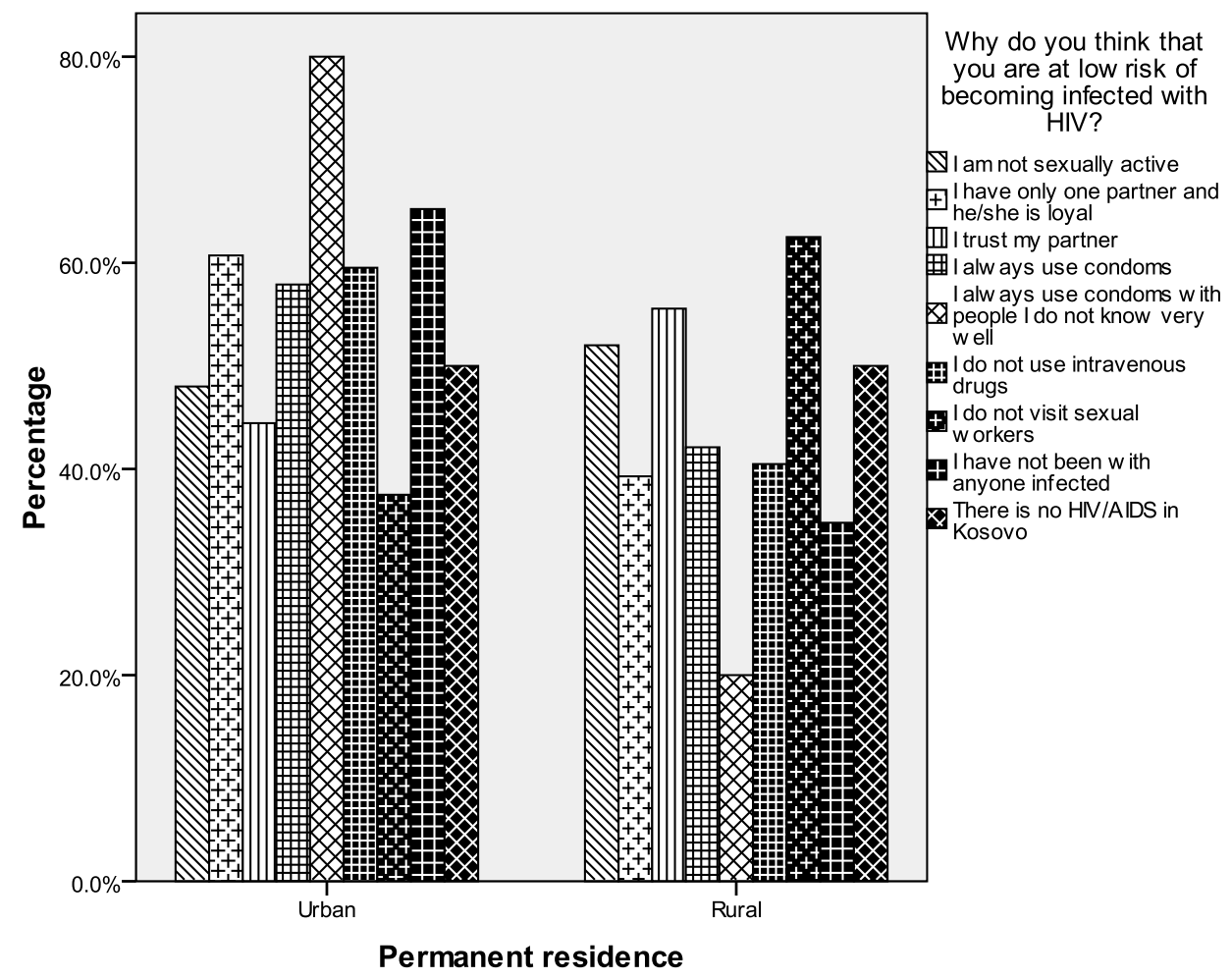

Figure 7. Why do you think that you are at low risk of becoming infected with HIV, according to permanent residence?

$[\mathrm{r}(2,199)=2.33, p=0.128]$. The average level of knowledge among men was $\mathrm{X}=23.0$ and $\mathrm{SD}=3.3$, while the average knowledge among women was $\mathrm{X}=23.6$ and $\mathrm{SD}=3.0$ (see Table 1). Although women have slightly more knowledge than men, differences are not significant, and therefore one cannot claim that gender affects knowledge on HIV/AIDS.

Furthermore, in terms of the correlation between the field of study and level of knowledge, the following results were found: average knowledge in the Department of Psychology was $\mathrm{X}=24.2$ and $\mathrm{SD}=2.2$; average knowledge in the Faculty of Medicine was $\mathrm{X}=24.3, \mathrm{SD}=3.1$; average knowledge in the Department of Chemistry was $\mathrm{X}=22.4$ and $\mathrm{SD}=3.2$, and average knowledge in the Faculty of Electrical Engineering and Computer was $\mathrm{X}=22.3$ and $\mathrm{SD}=3.0$ (see Table 2). Differences are significant $[\mathrm{r}(4,199)=6.72, p=0.000]$. This shows that the field of study has a significant correlation with the level of knowledge about HIV/AIDS. We can say that the field of study has impact on the level of knowledge: students of Psychology and Medicine have a higher level of knowledge compared to those of the Department of Chemistry and Faculty of Electrical Engineering and Computer.

Concerning the correlation between area of residence and the level of knowledge, the following results were found: average knowledge in urban areas was: $\mathrm{X}=23.6$ and $\mathrm{SD}=3.4$ and the average knowledge in rural areas was $X=22.8$ and SD $=2.8$ (see Table 3). Therefore, differences are not significant $[\mathrm{r}(2,199)=3.11, p=0.079]$. This shows that there is no significant correlation between the area of permanent residence and the level of knowledge on HIV/AIDS.

Analyses on the correlation between gender and risk perception do not show a significant correlation $[\mathrm{r}(2,199)$ $=0.975, p=0.325]$. The average risk perception for men was $\mathrm{X}=9.5$ and $\mathrm{SD}=2.6$, while the average risk perception for women was $\mathrm{X}=9.1$ and $\mathrm{SD}=2.8$ (see Table 4). This shows that there is no correlation between gender and perception of risk.

In terms of correlation between field of studies and risk perception, the following results have been found: average risk perception in the Department of Psychology was $\mathrm{X}=9.0$ and $\mathrm{SD}=2.4$; average risk perception in the Faculty of Medicine was $\mathrm{X}=9.8$ and $\mathrm{SD}=2.7$; average risk perception in the Department of Chemistry was $\mathrm{X}=9.2$ and $\mathrm{SD}=2.7$, and average risk perception in the Faculty of Electrical Engineering and Computer was $\mathrm{X}=$ 
9.4 and SD $=3.1$ (see Table 5), while differences are not significant $[\mathrm{r}(4,199)=0.775, p=0.509]$. This shows that there is no significant correlation between the area of studies and risk perception from HIV/AIDS.

Moreover, concerning the correlation between area of permanent residence and perception of risk, the following results have been found: average risk perception in urban residence was: $\mathrm{X}=9.3$ and $\mathrm{SD}=2.8$, average perception of risk in rural areas was: $\mathrm{X}=9.4$ and $\mathrm{SD}=2.7$ (see Table 6), while the differences are not significant $[r(2,200)=0.69, p=0.793]$. This indicates that there is no significant correlation between the area of permanent residence and perception of risk from HIV/AIDS.

Table 1. Impact of gender on the level of knowledge.

\begin{tabular}{ccc}
\hline Gender & Mean $(\mathbf{X})$ & Standard Deviation (SD) \\
\hline Male & 23.0 & 3.3 \\
Female & 23.6 & 3.0 \\
\hline
\end{tabular}

Table 2. Influence of study field on the level of knowledge.

\begin{tabular}{ccc}
\hline Field of Study & Mean (X) & Standard Deviation (SD) \\
\hline Department of Psychology & 24.2 & 2.2 \\
Faculty of Medicine & 24.3 & 3.1 \\
Department of Chemistry & 22.4 & 3.2 \\
Faculty of Electrical Engineering and Computer & 22.3 & 3.0 \\
\hline
\end{tabular}

Table 3. Impact of permanent residence on the level of knowledge.

\begin{tabular}{ccc}
\hline Permanent Residence & Mean $(\mathbf{X})$ & Standard Deviation (SD) \\
\hline Urban & 23.6 & 3.4 \\
Rural & 22.8 & 2.8 \\
\hline
\end{tabular}

Table 4. Impact of gender on the perception of risk.

\begin{tabular}{ccc}
\hline Gender & Mean $(\mathbf{X})$ & Standard Deviation (SD) \\
\hline Male & 9.5 & 2.6 \\
Female & 9.1 & 2.8 \\
\hline
\end{tabular}

Table 5. The impact of field of studies on the perception of risk.

\begin{tabular}{ccc}
\hline Field of Studies & Mean (X) & Standard Deviation (SD) \\
\hline Department of Psychology & 9.0 & 2.4 \\
Faculty of Medicine & 9.8 & 2.7 \\
Department of Chemistry & 9.2 & 2.7 \\
Faculty of Electrical Engineering and Computer & 9.4 & 3.1 \\
\hline
\end{tabular}

Table 6. Impact of area of permanent residence on perception of risk.

\begin{tabular}{ccc}
\hline Permanent Residence & Mean $(\mathbf{X})$ & Standard Deviation (SD) \\
\hline Urban & 9.3 & 2.8 \\
Rural & 9.4 & 2.7 \\
\hline
\end{tabular}




\section{Discussion}

Results of this study indicate the persistence of uncertainty and misunderstanding about the ways of transmission of HIV. It is certain that a great extent of spreading of misunderstanding about possible ways of transmission of HIV leads to unfounded fear, which limits joint and daily activities with people living with HIV, and encourages social isolation of these people. Moreover, misconceptions about HIV transmission may urge stigmatization and discrimination against people living with HIV and AIDS.

Results of this research study have shown that women have a little more knowledge than men, yet differences are not significant, therefore we cannot say that gender influences knowledge about HIV/AIDS. This is also supported by United Nations Kosovo Team (2008), which has not shown significant gender-based differences in relation to knowledge about HIV/AIDS. In this research have been targeted young people aged 15 to 24 . These results are also supported by Leili, Elham and Farkhondeh (2008), which have not shown significant genderbased differences in relation to knowledge about HIV/AIDS. However, the study by Biswas (2004) has shown that there are gender-based differences in relation to knowledge about HIV/AIDS. According to the Biswas (2004) males have a higher level of knowledge about HIV/AIDS than females.

On the other hand, the field of studies has a significant correlation with the level of knowledge about HIV/ AIDS. Thus, the fields of study: Psychology, Medicine, Chemistry, and Electrical and Computer Engineering affect the level of knowledge about HIV/AIDS. Students of the Department of Psychology and of the Faculty of Medicine have a higher level of knowledge about HIV/AIDS compared to the two other fields-Chemistry and Electrical and Computer Engineering. Contradictory reports have been published previously regarding the differences between the faculties. For example, the study conducted by Serlo (1999) showed minimal differences between the faculties regarding the knowledge about HIV/AIDS.

Study results show that there is no significant correlation between the area of permanent residence and the level of knowledge on HIV/AIDS. At the other hand, other studies report contradictory results. For example, the study conducted by Rahman (2009) showed that a wider gap exists between urban and rural areas regarding knowledge about AIDS, where every 8 out of 10 urban women know about AIDS but almost half of the rural women still do not know about AIDS. Also, a study conducted in the Nepal showed that urban people have more knowledge about modes of HIV transmission (Neupane, Nichols, \& Thapa, 2003).

Analysis on the relationship between gender and risk perception did not show a significant correlation. This is supported by Anderson, Beutel and Maughan (2007) where it is indicated that most respondents viewed themselves at no risk or small risk of HIV infection. At the other hand, a correlation between gender and perception of risk was shown in this study (2007), where women show a higher level of risk perception than men. The study conducted in South Africa showed that there may be gender-based differences, due to the large number of cases of HIV/AIDS in Africa, especially the large number of women and children infected. At the other hand, our study shows that there is no significant correlation between the area of studies and risk perception from HIV/AIDS, also there is no significant correlation between the area of permanent residence and perception of risk from HIV/AIDS.

\section{Conclusion}

Knowledge about HIV/AIDS among students is incomplete, namely there are misconceptions regarding ways of HIV transmission. Major misconceptions about HIV transmission concern sharing of toilet seats, daily social contacts (handshakes, hugs), feeding from the same plate with a person living with HIV, transmission of HIV from mosquito bites, etc.

While Kosovo is a country with a low level of prevalence of HIV/AIDS, yet with evident factors for increasing the number of HIV infections, there is a convincing need for implementing prevention programmes and measures addressing needs of the population, with particular emphasis on vulnerable groups and also there is a huge need for future researches with the large number of sample to show in details the level of knowledge and risk perception toward HIV.

Since this research has shown that students do not have full knowledge about HIV/AIDS, respectively that there are misconceptions about ways of transmission of HIV; that there is a high level of stigma among them towards people living with HIV/AIDS and that the perception of risk from HIV/AIDS is very low, then recommendations for action lines have been developed in accordance with the results of research. They are aimed at developing prevention programmes which would include activities related mainly to continuing education pro- 
grammes (within and outside educational institutions, especially through TV programmes and peer education), aimed at increasing knowledge and creating protective behavior against HIV among young people in Kosovo.

\section{References}

Anderson, K. G., Beutel, A. M., \& Maughan-Brown, B. (2007). HIV Risk Perceptions and First Sexual Intercourse among Youth in Cape Town, South Africa. International Family Planning Perspectives, 98-105.

Biswas, M. M. (2004). Gender Differences in Knowledge, Attitudes and Prevention of HIV/AIDS/STI among Youth in West Bengal, India. In The 132nd Annual Meeting.

Godinho, J., Jaganjac, N., Eckertz, D., Renton, A., \& Novotny, Th. (2005). HIV/AIDS in the Western Balkans Priorities for Early Prevention in a High-Risk Environment. Washington DC: The World Bank. http://dx.doi.org/10.1596/0-8213-6394-8

Kosovar AIDS Committee (2004-2008). Kosovar Strategy for HIV/AIDS Prevention 2004-2008. Prishtinë: Kosovar AIDS Committee.

Kosovo Ministry of Health (2001). Knowledge of School Youth on AIDS. Prishtinë: Office for HIV/AIDS.

Leili, S., Elham, S., \& Farkhondeh, S. (2008). A Population-Based Survey of HIV/AIDS Knowledge and Attitudes in General Public, Bandar-Abbas, Iran. Pakistan Journal of Medical Sciences, 24, 838-844.

National Institute of Public Health (2001). Knowledge, Attitude and Habits of Youngsters to Sexual and Reproductive Health. Prishtinë: National Institute of Public Health.

Neupane, S., Nichols, D., \& Thapa, S. (2003). Knowledge and Beliefs about HIV/AIDS among Young People in Urban Nepal. Asia Pacific Population Journal, 18, 39-52.

Rahman, M. (2009). Determinants of Knowledge and Awareness about AIDS: Urban-Rural Differentials in Bangladesh. Journal of Public Health and Epidemiology, 1, 014-021.

Serlo, K. L. (1999). Attitudes of University Students towards HIV/AIDS. Journal of Advanced Nursing, 29, 463-470. http://dx.doi.org/10.1046/j.1365-2648.1999.00909.x

United Nations Kosovo Team (2008). Knowledge, Attitudes, Practices and Behavior of Young People in Kosovo on HIV/ AIDS. Prishtinë: United Nations Kosovo Team. 
Scientific Research Publishing (SCIRP) is one of the largest Open Access journal publishers. It is currently publishing more than 200 open access, online, peer-reviewed journals covering a wide range of academic disciplines. SCIRP serves the worldwide academic communities and contributes to the progress and application of science with its publication.

Other selected journals from SCIRP are listed as below. Submit your manuscript to us via either submit@scirp.org or Online Submission Portal.
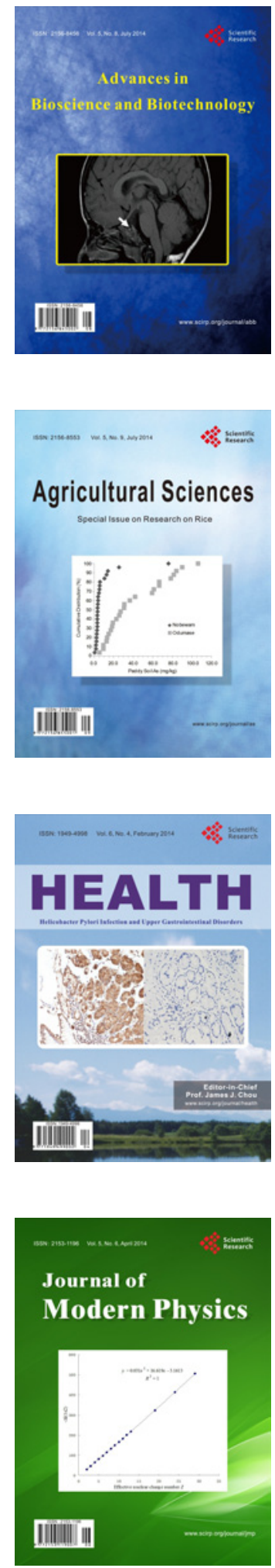
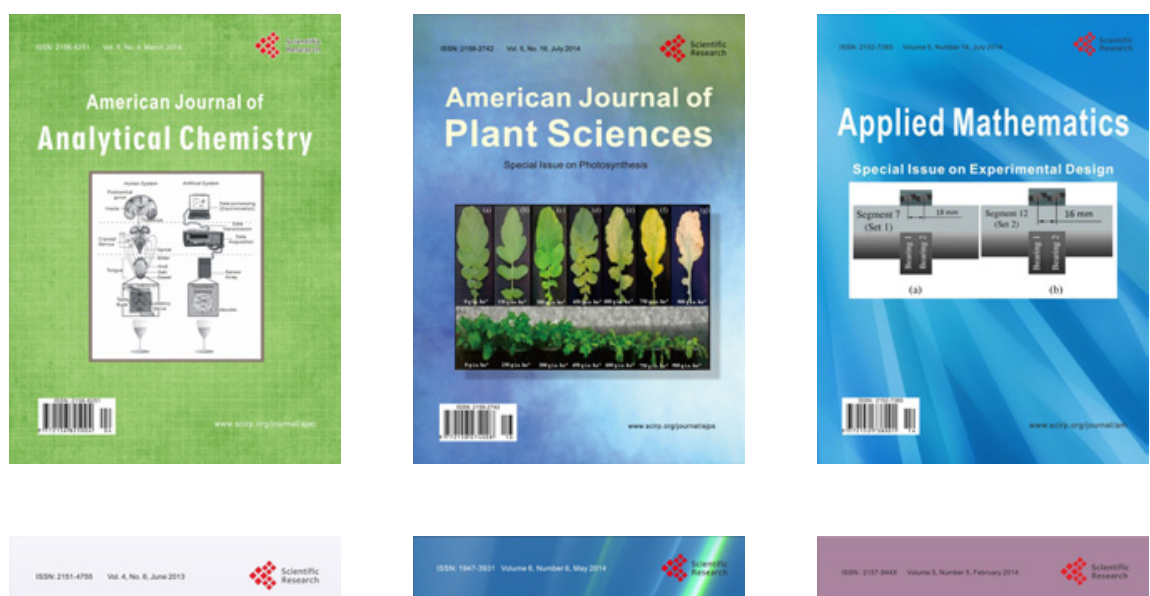

Creative Education
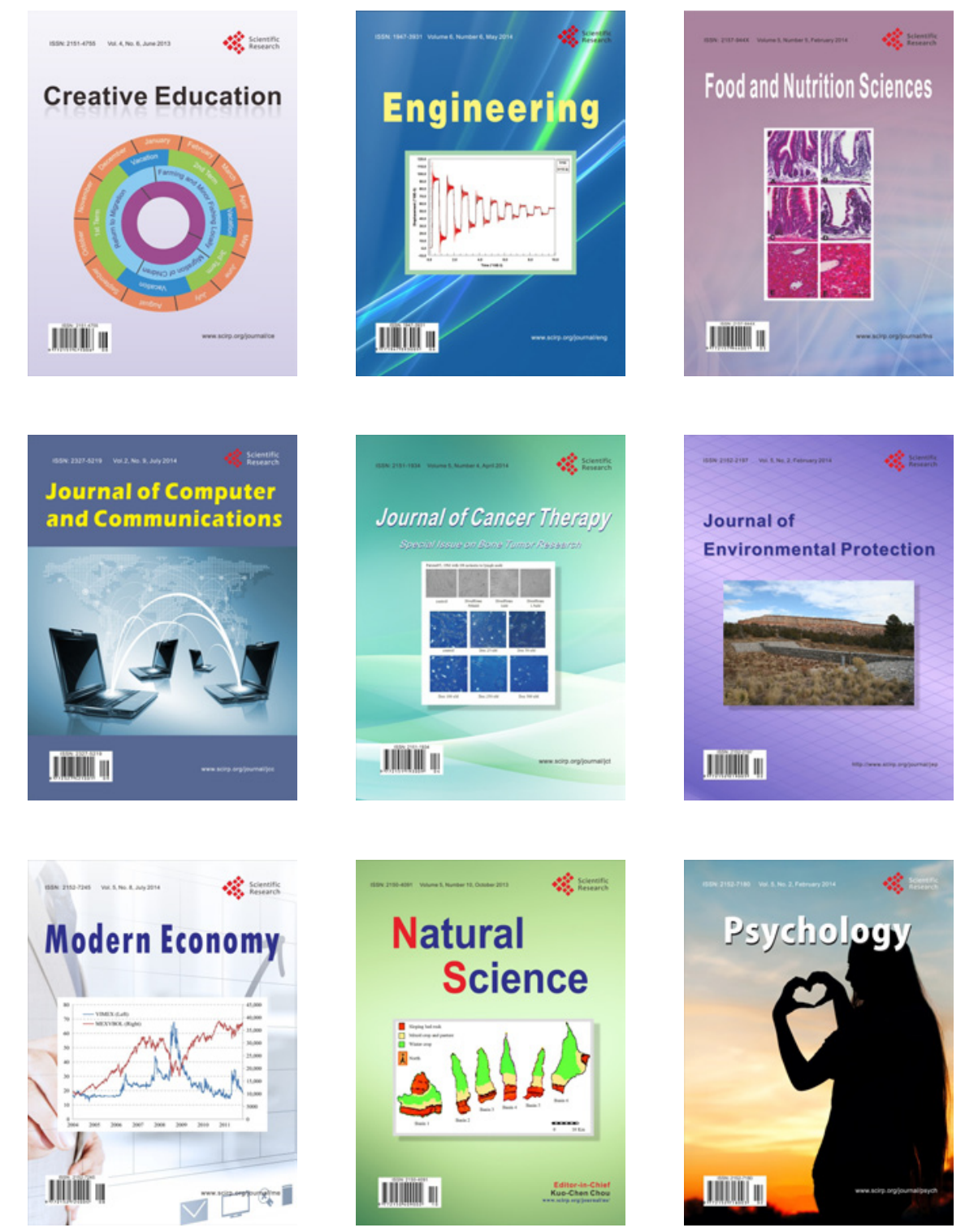